\title{
Paisaje, patrimonio y turismo: expresión sistémica en la integración del Corredor Bioceánico Central
}

\author{
Luisa Mattioli* \\ Consejo Nacional de Investigaciones Científicas y Técnicas (Argentina)
}

\begin{abstract}
Resumen: La transformación territorial a la que está expuesto el Departamento rural de Iglesia, en San Juan-Argentina, presenta oportunidades como amenazas de desarrollo, bajo la presión de diferentes procesos. La consolidación del corredor Bioceánico Central, vaticina nuevos escenarios con la construcción del Túnel Internacional Paso de Agua Negra, lo que promueve la integración territorial y demanda la provisión de infraestructura y servicios complementarios. Esto habilita a pensar posibilidades de desarrollo del Departamento como también en formas más integrales de planificación, ante falencias instrumentales y territoriales. El objetivo de este trabajo es exponer una revisión crítica, discusión conceptual y metodológica de enfoques sobre Patrimonio, Paisaje y Turismo, abordado en "El Plan de ordenamiento y desarrollo territorial para el departamento de Iglesia". Se pretende aportar una aproximación teórica-metodológica en la comprensión de la realidad sistémica, desde la consideración del funcionamiento del paisaje y una clasificación patrimonial como ejes estructuradores, para la reproducción del turismo. Esto permite la definición de criterios esenciales de planificación rural, donde la vocación turística-patrimonial sea un factor predominante. La discusión y síntesis, plantea la importancia sistémica de dichos conceptos como insumo para la planificación y ordenamiento territorial. Abordar situaciones contextuales de desarrollo alternativo, resulta ser un reto interdisciplinar para la conservación patrimonial, ante la posible enajenación local del territorio.
\end{abstract}

Palabras Clave: Planificación integrada; Paisaje; Patrimonio; Turismo.

Landscape, Heritage and Tourism: Systemic expression in the integration of the Central Bioceanic Corridor

Abstract: The territorial transformation being undergone by the Rural Department of Iglesia in San Juan-Argentina opens up "opportunities" for development that may represent threats to its sustainability. The consolidation of the Central Bio-Oceanic corridor foresees new scenarios such as the construction of the Paso de Agua Negra International Tunnel, aimed at promoting integration and demanding, as a result, provision of utilities and amenities that broaden the horizon for regional planning, to compensate for previous partial projects. The aim of this research is to give a critical review of previous conceptual and methodological approaches to Heritage, Landscape and Tourism, as addressed in "The Plan of land use and territorial development for the rural area of Iglesia ". The aim is to provide a theoretical-methodological approach that allows for an understanding of the systemic reality and of how landscape and heritage can be classified in a functional manner to structure tourism. Essential rural planning criteria are considered within the framework of the nascent heritage tourism vocation. The discussion and conclusions underline the systemic importance of these concepts as an input for all planning and territorial organisation. The broaching of alternative contextualised situations of development poses interdisciplinary challenges to heritage conservation and possible alienation of the location from its territory.

Keywords: Integrated planning; Heritage; Tourism; Landscape.

\section{Introducción}

El Departamento Iglesia, está ubicado al norte de la provincia de San Juan y al centro oeste de Argentina. Coincide con ambientes rurales áridos y semi-áridos de oasis de riego. Iglesia entendida

* Consejo Nacional de Investigaciones Científicas y Técnicas (Argentina); E-mail: mss30291@gmail.com; https://orcid. org/0000-0002-1126-0225 
Figura 1: Localización geográfica del Departamento de Iglesia, San Juan-Argentina.

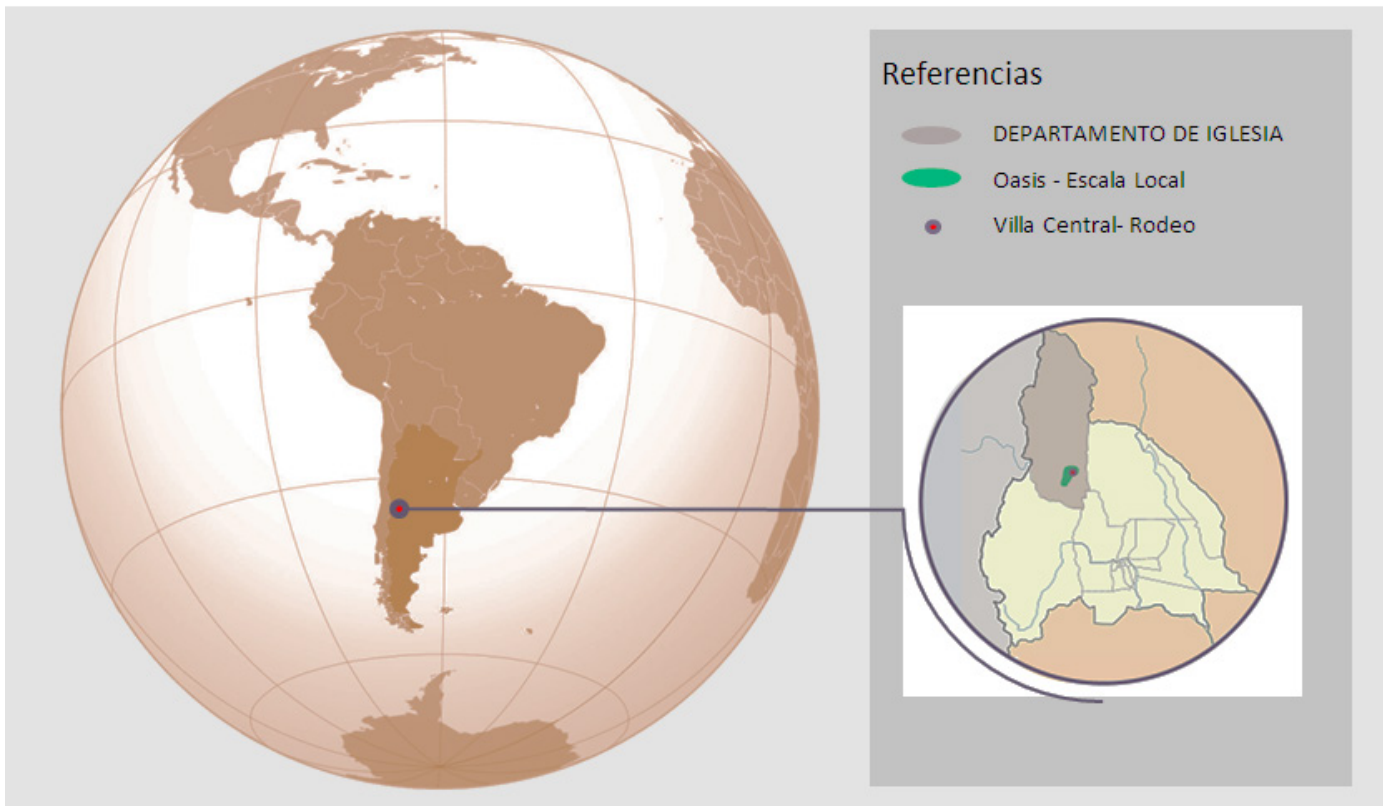

desde la micro-región de Rodeo ${ }^{1}$, posee un valioso patrimonio natural y cultural y se encuentra bajo la presión de diferentes procesos territoriales en diversas escalas. Las principales actividades económicas, se encuentran asociadas a la minería de enclave y el turismo. Un aspecto trascedente para el Departamento, constituye la propuesta de integración territorial, por medio del Corredor Bi-oceánico Central, formulada en el Plan Estratégico Territorial 2016 (PET), ratificada por la Iniciativa para la Integración de la Infraestructura Regional Suramericana (IIRSA), que modifica la configuración actual de infraestructura vial a partir de inversiones basadas en el diseño de una nueva red de corredores y pasos para facilitar la integración del territorio y la articulación con los mercados nacionales e internacionales (Ministerio del Interior, Obras Públicas y Vivienda , 2017). Se crea así, la Empresa Binacional Túnel Agua Negra² (EBITAN), organismo responsable de la Contratación del Diseño del Proyecto Ejecutivo y Construcción del Túnel Internacional Paso de Agua Negra (EBITAN, 2016). Esta integración territorial sumada a los procesos existentes, demanda la provisión de infraestructura y servicios complementarios para esta obra, que se traducirá en un impacto territorial sustancial, a la vez que crean nuevas oportunidades para la población local. "Si bien las áreas rurales son, por definición productivas, parte de que esa productividad depende y es condicionada por el nivel de conservación de los ecosistemas, la sustentabilidad de los recursos naturales y la protección de especies valiosas o amenazadas" (Ministerio de Planificación Federal, Inversión Pública y Servicios, 2011, pág. 86). Para ello este organismo por medio del lineamiento estratégico $\mathrm{N}^{\circ} 8$, para el OT del Avance II del "Plan Estratégico Territorial" (PET), Programa Argentina Rural, insta a la formulación de planes de usos del suelo rural a escalas micro-regionales.

Iglesia posee un rol estratégico en la provincia, asignando a Villa Rodeo y a Las Flores (último tramo argentino del Corredor Bioceánico), el rol de centros de provisión de servicios especializados para los servicios del transporte y las comunicaciones. Con la concreción de este corredor, el turismo tendría un gran impulso. Esto amerita su consideración como un complejo fenómeno que atraviesa las distintas dimensiones del sistema territorial. Involucra directamente a la población rural y su relación con su patrimonio cultural y natural. Lo anteriormente dicho, define las posibilidades de desarrollo del Departamento.

El contexto normativo provincial, adolece de legislación sobre planificación territorial y en consecuencia, no existe Ley de Ordenamiento Territorial, ni de suelo urbano o rural. La gestión territorial se ejecuta con instrumentos sectoriales (Código Urbanístico, la Ley de Aguas, la Ley de Protección del 
Patrimonio, de Manejo de reservas naturales, entre otras) sin coordinación con otras áreas y niveles de gobierno, sólo desde el ámbito urbano. En este marco, la gestión municipal de Iglesia, ante la carencia de directrices que orientaran su desarrollo, solicitó asistencia a la Dirección Nacional de Preinversión Municipal (DINAPREM). Esto se realizó para fortalecer su condición estratégica provincial y nacional, con la formulación de un Plan Estratégico, bajo el Programa Multisectorial de Preinversión IV Préstamos BID 2851 OC-AR.

En síntesis, el proceso de transformación territorial que implicará a futuro, la construcción del paso transfronterizo de Agua Negra, con la consecuente consolidación del Corredor Bioceánico Central, implica pensar en el posible desarrollo del Departamento de Iglesia. Por ello, la línea de investigación, se centra en responder a la siguiente pregunta: ¿Es posible la búsqueda de un desarrollo sostenible sobre la base del balance turístico entre el rendimiento económico, uso colectivo y la defensa del patrimonio cultural/natural en el territorio, considerando el funcionamiento del Paisaje?

En función a este interrogante y como objetivo del trabajo, se expone la revisión crítica, discusión conceptual y metodológica de enfoques sobre Patrimonio, Paisaje y Turismo, abordado en el "Plan de ordenamiento y desarrollo territorial para el departamento Iglesia: los desafíos frente a la integración" (PODT). El mismo tiene la finalidad de aportar una aproximación teórica-metodológica en la comprensión de la realidad sistémica. Por ello se plantea una revisión crítica de la literatura, reflexión y vinculación de los conceptos propuestos, que rigen el PODT para lograr un posicionamiento de diagnóstico territorial. Se busca indagar en formas más integrales de metodologías de planificación y OT involucrando dichos conceptos, para anticipar y abordar los posibles impactos que supone la consolidación de este Corredor Bioceánico Central.

El Plan impulsado por el Municipio de Iglesia, se muestra como resultado de un proceso colectivo, bajo enfoques del uso múltiple del territorio, de paisaje y de cuencas (Nozica, 2017). Su planteamiento, se cimenta en la búsqueda de opciones que visualicen la realidad compleja, acorde a territorios de oasis rurales y abordadas en investigaciones previas del equipo de investigación (Mattioli, 2016, 2019) (Nozica \& Henríquez, 2014) (Nozica, Taber, Arroqui, \& Fernandez, 2009) (Nozica, De Paolis, \& Henríquez, 1996). Se presume que los conceptos arriba nombrados, debieran ser incorporados como base fundamental del proceso de diagnóstico, por lo que se intenta demostrar la importancia sistémica de los mismos como insumo para la planificación y ordenamiento territorial (OT).

Según lo antedicho y en función a la pregunta rectora, se plantean a continuación las hipótesis que orientan este trabajo:

H1. "La planificación integrada de territorios rurales como el Departamento de Iglesia, no pueden analizarse sin la concepción sistémica que plantea el concepto de Paisaje para entender su estructuración y así asumir el compromiso de sostenibilidad ambiental.

H2. El concepto del Paisaje, habilita la concreción de proyectos Turísticos-Patrimoniales según las restricciones y limitaciones que su funcionamiento indique.

H3. La articulación del territorio, pensando en términos de Patrimonio, permitiría una estrategia de desarrollo en base al Turismo, sentando las bases para su defensa y conservación.

H4. La valoración Patrimonial local, es condición indispensable para la conservación y gestión del mismo asumiendo el compromiso de defender la identidad cultural.

H5. El turismo en Iglesia, es un factor determinante para el Desarrollo local.

Se verifica que las hipótesis establecidas, destacan la importancia en la planificación del paisaje en territorios rurales de oasis. El paisaje se manifiesta como unidad viva, orgánica y de funcionamiento complejo, que aglutina el patrimonio local, implica un posicionamiento, negociación y participación de todos los actores locales. De esta manera se muestra como resultado una metodología de clasificación patrimonial en relación a la concepción del Paisaje, que permiten la reproducción del turismo bajo condiciones de sostenibilidad. Se evidencia la importancia a la que refieren estos conceptos en territorios que presenten dinámicas similares de vocación turística-patrimonial, por lo que se definen criterios esenciales de planificación rural.

La identidad será producto de estas interacciones compartidas, las cuales se consolidan a partir de su medio. Así, el concepto de Paisaje y en consecuencia el de Patrimonio, se conciben como eje estructurador a tener en cuenta en la ordenación del territorio. El Turismo, como vocación territorial local dependiente de los recursos patrimoniales, funciona como factor estratégico dinamizador del desarrollo y como facilitador de la protección, conservación y preservación patrimonial local. El turismo tomado como estrategia desde la multi-dimensionalidad, adquiere relevancia por la variedad de actividades 
económicas asociadas a su funcionamiento. Como principal motor, se presenta a la comunidad que le da legitimidad y el sustento cultural local. Por tanto, la pérdida de las expresiones de singularidad regional deja expuesto el reto interdisciplinar, que implica formas metodológicas más integrales.

\section{Marco Teórico. Revisión crítica de la literatura}

\subsection{Ordenamiento y desarrollo: el reto frente a la planificación no situada.}

Los planes de OT, son el producto del proceso de planificación. Este proceso deriva en dos instrumentos: "el marco normativo, que es el soporte regulatorio que sostiene legalmente los planes territoriales, y la estrategia de comunicación y participación, que colabora en la eficiencia y legitimación de las intervenciones" (Subsecretaría de Planificación Territorial de la Inversión Pública, 2016, pág. 04). El OT "es un proceso de carácter técnico-político-administrativo, con el que se pretende configurar en el largo plazo, una organización de uso y ocupación del territorio, acorde con las potencialidades y limitaciones de este, con las expectativas y las aspiraciones de la población y con los objetivos de desarrollo" (Massiris, 2005, págs. 15-16). Expresa el modelo territorial a seguir, con las estrategias de actuación sobre la realidad, a fin de evolucionar hacia dicho modelo. Es un instrumento de planificación y gestión tendiente a elevar el nivel de vida de la población, expresando espacialmente las políticas de Estado. Por ello el desarrollo estará en función de esta política (Massiris, 2012; Gudiño, 2008). La Carta Europea de Ordenación del Territorio, señala que el OT es la "expresión espacial de las políticas económicas, sociales, culturales y ecológicas de la sociedad. Es a la vez una disciplina científica, una técnica-administrativa y una política concebida como un enfoque interdisciplinario y global" (Consejo de Europa, 1983). El término OT ha tenido desde hace dos décadas, una utilización cada vez más amplia en los discursos públicos sobre desarrollo referidos a las temáticas ambientales y sociales. Pese a ello, la gran dispersión de conceptos referidos al tema genera confusiones y debilidades metodológicas, lo que reafirma la inseguridad y discontinuidad de las políticas territoriales (Hildenbrand, 1996).

Muchas veces los planes de ordenamiento, aunque reconocen la transversalidad e intersectorialidad del OT, no resuelven la necesidad de concurrencia o articulación de los diversos planes e incluso están soportados por normas legales distintas, concebidas independientemente (Massiris, 2002). Se critican planteamientos y posturas sobre la planificación, porque enfatizan en demasía la formación de la estrategia, como un proceso deliberado de pensamiento consciente en el sentido de que la acción debe fluir de la razón y que ésta, sólo puede implementarse cuando está completamente formulada. Se critica la excesiva formalidad, la separación tajante en etapas, el aislamiento del proceso decisorio, la planificación como responsabilidad principal de los planificadores y el no involucramiento en el diseño de los responsables de la ejecución (Lira, 2006). La mayoría de los planes en nuestras regiones, quedan como acabados planes impresos sin ser aplicados en la práctica, debido a que no se han producido las reformas estructurales necesarias, relacionados con la distribución y coordinación de funciones de las instituciones con competencia en el tema, como también con la asignación de recursos necesarios para efectivizar el proceso (Berón, Padilla, \& Rapali, 2013). Los procesos metodológicos, difícilmente tienen en cuenta todas las escalas intervinientes. Generalmente culminan en una sumatoria de planes y proyectos que no pueden visualizar de forma holística los procesos que ocurren en el territorio, aumentando su vulnerabilidad (Mattioli, 2016).

En Argentina, la planificación intentó proyectar el futuro, pero no pudo emplazar los procesos más profundos del desarrollo social, urbano y rural que involucran los alcances mismos del poder público en relación a los mercados, que son los que verdaderamente conducen los procesos territoriales ante la falta de instrumentos legales que operen sobre el uso del suelo. Esta situación hace que algunos gobiernos locales vuelvan a revisar la planificación, al tiempo que desarrollan nuevos instrumentos para permitir minimizar los procesos especulativos en el mercado del suelo urbano siendo lo rural un área dependiente de la primera (Nozica \& Taber, 2011).

Metodológicamente, el espacio rural merece una atención diferente al urbano. Los diferentes procesos y tipos de ruralidad, determinan distintas dinámicas a las urbanas. Según Urzainki Mikeleiz A., el espacio rural se considera un sistema dinámico en el que los elementos físicos y culturales están fuertemente trabados, un sistema de actividades y modos de vida que integran íntimamente población y medio ambiente físico (1993). En estos lugares, "las relaciones territoriales, los procesos ecológicos, la distribución de recursos, la necesidad de expansión de la frontera agrícola, las presiones externas de posesión, dominación y manejo de recursos, como las internas de supervivencia, exclusión, marginación, 
y pobreza, son entre muchos otros factores, determinantes de graves conflictos sobre los recursos de carácter estratégico para un territorio y el Estado" (Mattioli, 2016).

Los territorios rurales de Iglesia responden al tipo de oasis. Según la definición otorgada por el Cricyt, la palabra "oasis" deriva de los términos coptos ueh (habitar) y saa (beber), que proviene de diversas regiones áridas del mundo donde el hombre puede habitar gracias al manejo del agua (Abraham, 2015). Iglesia, se caracteriza una sucesión de oasis envueltos por desiertos con particularidades similares en cuanto a la utilización del recurso vital del agua, lo que provoca y mantiene a la población en pequeñas superficies, con bajas densidades de población en paisajes contrastantes (Nozica \& Henríquez, 2014).

Existe una necesidad creciente de integración interdisciplinaria y multidimensional de la planificación, que considere las diferentes escalas espaciales y temporales tanto como los sujetos, lugares y procesos de la realidad. Considerando este reto, se expone el PODT de Iglesia que plantea un acercamiento teórico-metodológico apropiado a las condiciones particulares al ambiente natural, construido y socio-cultural, así como a las características políticas-administrativas del Departamento.

El estudio del territorio se trabajó desde el enfoque de cuencas como unidad ambiental, debido a que posibilita evaluar y explicar las externalidades resultantes de los diferentes usos del suelo. La propuesta del uso múltiple del territorio, amplía la posibilidad de opciones de transformación del territorio evaluando los impactos que produce acrecentar el potencial productivo, en términos de riesgos y consumo de agua, tanto en el área de secano como de oasis. Estos conceptos se complementan con el de Paisaje, que incluye las transformaciones del paisaje natural en paisaje cultural por la transformación del hombre (Nozica, Graciela (Coord.), 2017). Este planteo se aborda desde la metodología de Rolando García (2006), sobre "Sistemas Globales Complejos", para la comprensión y explicación del funcionamiento de los sistemas complejos de manera iterativa, sin generar una estructura rígida de aplicación y de alta aplicabilidad para cualquier investigación de sistemas territoriales.

La propuesta, acuerda un marco epistémico en conjunto. A continuación se presentan los conceptos de relevancia que permiten un posicionamiento para la comprensión de la estructura territorial. Se pretende brindar una discusión para lograr situaciones contextuales de desarrollo ante la posible enajenación del territorio local.

\subsection{Concepción, crítica y posicionamiento sobre Patrimonio y Paisaje}

El patrimonio cultural y natural, forman parte de los bienes inestimables e irremplazables no sólo de cada nación sino de toda la humanidad y constituyen una seña de identidad. La UNESCO está convencida de que el componente cultural fuerte, consigue resultados sostenibles, inclusivos y equitativos, abordando la cuestión del desarrollo con prioridad sobre el ser humano, el respeto mutuo y el diálogo entre las diferentes comunidades (UNESCO (a), 2017).

En 1972 se constituye un sistema de patrimonio mundial en torno a la Convención sobre la Protección del Patrimonio Mundial, Cultural y Natural, adoptada por la UNESCO. Nuestro país es Estado miembro desde 1978 (Ley 21.836). Esta convención propone promover la identificación, la protección, la conservación, la presentación y transmisión del patrimonio cultural y natural de todo el mundo considerado especialmente valioso para la humanidad. Cuando se determina que un bien posee un valor universal excepcional, es decir un significado natural y/o cultural que es tan excepcional como para trascender las fronteras naciones y constituir un interés común para las generaciones presentes y futuras, se lo inscribe en la Lista de Patrimonio Mundial. La misma resulta ser un inventario de bienes cuyo valor amerita ser sostenido, protegido, conservado, administrado, monitoreado y comunicado de manera especial. La Convención crea y define la competencia de los actores involucrados en el sistema de patrimonio mundial: el Comité Intergubernamental de Patrimonio Mundial, el Centro de Patrimonio Mundial, el Fondo de Patrimonio Mundial y los órganos asesores (UICN; ICOMOS; ICROM). En nuestro país, se creó el Comité Argentino del Patrimonio Mundial con competencia en patrimonio mundial, natural y cultural, que coordina y articula el trabajo de los actores vinculados al patrimonio mundial en Argentina (Ministerio de Educacón y Deportes. Presidencia de la Nación Argentina, 2017).

En la provincia de San Juan, la ley $\mathrm{N}^{\circ} 6801$ (1997) define en su artículo 1, que: "debe declararse de interés provincial la protección, conservación, restauración, acrecentamiento y difusión de todos aquellos bienes que conforman el Patrimonio Cultural y Natural de la Provincia de San Juan (...) como testimonio para el conocimiento y desarrollo cultural de las generaciones futuras". En su artículo 2, que: "se consideran integrantes del Patrimonio Cultural y Natural de la Provincia de San Juan, todos aquellos bienes que, material y/o culturalmente, reportan un interés cultural, antropológico, prehistórico, 
arqueológico, paleontológico, histórico, etnológico (...) que significan o pueden significar un aporte relevante para el desarrollo cultural de la Provincia de San Juan".

La definición aportada por la UNESCO (b) (Convención sobre la Protección del Patrimonio Mundial Cultural y Natural, 1972), considera como "patrimonio Cultural" a los monumentos (obras arquitectónicas, de escultura o de pintura monumentales, elementos o estructuras de carácter arqueológico, inscripciones, cavernas y grupos de elementos, que tengan un valor universal excepcional desde el punto de vista de la historia, del arte o de la ciencia); los conjuntos (grupos de construcciones, aisladas o reunidas, cuya arquitectura, unidad e integración en el paisaje les dé un valor universal excepcional desde el punto de vista de la historia, del arte o de la ciencia); los lugares: obras del hombre u obras conjuntas del hombre y la naturaleza así como las zonas incluidos los lugares arqueológicos que tengan un valor universal excepcional desde el punto de vista histórico, estético, etnológico o antropológico. Considera como "patrimonio natural": los monumentos naturales constituidos por formaciones físicas y biológicas o por grupos de esas formaciones que tengan un valor universal excepcional desde el punto de vista estético o científico; las formaciones geológicas y fisiográficas y las zonas estrictamente delimitadas que constituyan el hábitat de especies animal y vegetal amenazadas, que tengan un valor universal excepcional desde el punto de vista estético o científico; y los lugares naturales o las zonas naturales estrictamente delimitadas, que tengan un valor universal excepcional desde el punto de vista de la ciencia, de la conservación o de la belleza natural. Se declara también que es incumbencia de cada Estado Parte en la presente Convención de identificar y delimitar los diversos bienes situados en su territorio.

Unesco distingue dos tipos de patrimonio cultural: tangible o material (creada en la $17^{\mathrm{a}}$ Convención

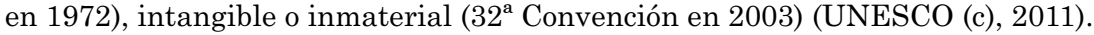

Hoy en día, el "patrimonio ya no es un sistema cerrado sino que ha sufrido un proceso de democratización hasta convertirse en nuestros días en un campo abierto. Se afianza el criterio de "significado para los ciudadanos", es decir, la capacidad del bien patrimonial de "satisfacer las demandas reclamadas socialmente". Y uno de los hechos más significativos de nuestra época es incorporar el medio ambiente, al acervo de los valores culturales, sociales y humanos de la sociedad actual (Ảlvarez Munárriz, 2010).

La definición de Paisajes culturales, aportada por el Centro del Patrimonio Mundial de la UNESCO, afirma que son bienes culturales y representan las "obras conjuntas del hombre y la naturaleza". Estos paisajes ilustran la evolución de la sociedad humana y sus asentamientos a lo largo del tiempo, condicionados por las limitaciones y/u oportunidades físicas que presenta su entorno natural y por las sucesivas fuerzas sociales, económicas y culturales, tanto externas como internas (Centro del Patrimonio Mundial de la UNESCO , 2005, pág. 26). Esta definición se reduce a un contexto de gran valor que hay que conservar y proteger, como si se tratara de un resto fósil, como una imagen pregnante de esa relación hombre-naturaleza.

Se adhiere al concepto de Paisaje, desde una noción superadora de las cartas patrimoniales, centrando la mirada en los paisajes ordinarios en los que vive la gente, aquellos vividos por las personas. El Convenio Europeo del Paisaje, valora la dimensión cultural, ecológica, medioambiental y social del paisaje. "Este nuevo concepto expresa, por el contrario, el deseo de afrontar, de manera global y frontal, la cuestión de la calidad de los lugares donde vive la población, reconocida como condición esencial para el bienestar individual y social, para un desarrollo sostenible y como recurso que favorece la actividad económica" (Consejo de Europa, 2000). En Antropología social se priman los significados culturales, las percepciones, las representaciones y las imágenes que los miembros de un grupo social hacen de su territorio, la co-evolución de componentes culturales y físicos, que genera un paisaje cultural (Álvarez Munárriz, 2010). El Centro Argentino de Arquitectos Paisajistas (CAAP, 2017), adscribe al Convenio Europeo del Paisaje, (Florencia 10/2000), la Carta del Paisaje de Buenos Aires (Buenos Aires 06/2004) y la Carta de Lima (Lima 12/2004). La Carta Argentina del Paisaje redactada por la CAAP (2017), define al paisaje como una "construcción social desde una tradición cultural donde se despliegan conjuntamente, tanto la intencionalidad humana como los procesos biológicos y físicos de la naturaleza (...) espacio vital donde el hombre se relaciona con la naturaleza en forma individual o colectiva, objetiva y subjetivamente (con sentimientos y emociones), actuando en ella y modificándola con connotaciones ambientales, sociales, culturales, económicas, históricas y políticas. El paisaje influye sobre el Hombre y éste sobre el paisaje (...) constituye una realidad compleja en cambio permanente debido a la interacción entre los factores bióticos, abióticos y antrópicos". Carl Sauer desde el campo de la geografía, declara que el paisaje tiene elementos en interrelación que dan la realidad de conjunto, una totalidad que posee forma, estructura y función, y una posición en un sistema, sujeta a desarrollo, cambio y culminación. “(...) el paisaje posee una 
identidad que está sustentada en una constitución reconocible, límites, y una relación con otros paisajes, para constituir un sistema general. Su estructura y función están determinadas por formas integrantes, dependientes. Por tanto, se considera al paisaje, en cierto sentido, como poseedor de una cualidad orgánica" (Sauer, 2006, pág. 5). Esta definición se relaciona al campo de las ciencias naturales en relación a los atributos de la biodiversidad (composición, estructura y función), donde el paisaje resulta ser una categoría de análisis en los cuatro niveles de organización biológica de la biodiversidad (genes, especies, ecosistemas y paisajes) (ONU, 1992) (Mattioli \& Nozica, 2017). Estas últimas autoras, exponen la forma de concebir al concepto de Paisaje para definir unidades de diagnóstico, que respondan más adecuadamente a los procesos que suceden en el territorio adoptando el enfoque de cuencas y de oasis-secano.

Estas concepciones comienzan a interrelacionar ciencias, lo que caracteriza la complejidad sistémica y que afirma un abordaje interdisciplinar. Este enfoque es necesario ya que nuestra época global se impone ante lo local, generando la pérdida de las expresiones de singularidad regional como la imposición de lógicas diversas. Así, la planificación del paisaje como unidad viva, orgánica y sistema complejo implica un posicionamiento, negociación y participación de todos los actores locales para lograr una identidad compartida, consolidada a partir de su medio.

La Ley $\mathrm{N}^{\circ} 6.549$ (1994) nos habla de: "preservar y mejorar el ambiente, resguardar y proteger la dinámica ecológica y propiciar el desarrollo sustentable". Al referirse a la dinámica ecológica, el concepto del "paisaje", que incluye la biodiversidad, la región o eco-región junto a los procesos bio-geo-químicos, resulta ser indispensable para el análisis del territorio en términos ecológicos. El Patrimonio desde su visión antropocéntrica, permite evidenciar aquellos elementos culturales y naturales considerados significativos. Ellos, son los que componen la red de bienes de valor para la/s comunidad/es, definiendo los límites de lo que pertenece o no a cada una, según la escala territorial variable.

Por lo tanto al patrimonio, implica lo Natural y lo Cultural (tangible -mueble o inmueble- e intangible) que deben gestionarse para responder también a una armonía socio-ecológica.

El paisaje, como unidad de análisis, traspasa fronteras políticas administrativas y responde a las funciones ecosistémicas. Esta postura brinda la posibilidad de generar las unidades de diagnóstico más acorde a los procesos que interactúan en los territorios, para evaluar el sistema, atendiendo a nociones más equitativas de OT (Mattioli \& Nozica, 2017).

El reconocimiento y conservación del patrimonio es un derecho y resultado de un proceso de construcción social, un reto interdisciplinar desde las propias estrategias que puedan garantizar un patrimonio vivo adecuado al cumplimiento de su función social (López \& Vidargas, 2014) y ambiental. Se coincide que, la destrucción del patrimonio es una demostración de poder, como también, la conservación selectiva que el poder hace de un legado cultural determinado. Decidir qué es lo que se conserva, o qué nos representa será mucho más determinante que la destrucción y el olvido. En nombre del patrimonio, se vulneran las comunidades, no sólo desde su pérdida sino desde la dominación ideológica que es aún peor (López \& Vidargas, 2014).

Otro problema que destaca Nordenflycht, es el nostálgico y disfuncional discurso de la puesta en valor del patrimonio, que demuestra la crisis epistolar, que pasa por entender y asumir que nos encontramos en un escenario complejo actual, donde la velocidad del cambio supera exponencialmente nuestra capacidad de respuesta (2002). La pérdida de vigencia de cartas patrimoniales se evidencia en el momento en que el patrimonio tanto cultural como natural pasa a ser hoy, un objetivo de comercialización más que un verdadero rescate para la solidaridad con las generaciones futuras. No todo bien patrimonial local puede obtener una declaración de conservación. Desde la visión de conservación de biodiversidad, un fragmento, no soluciona los desequilibrios ambientales y mucho menos los sociales. Por ello se sostiene que la planificación territorial debe contrarrestar estas visiones sesgadas, integrando distintos tipos de saberes científicos y no científicos.

\subsection{El turismo, fenómeno dinamizador o destructor del patrimonio}

El Turismo Alternativo refiere a aquellos viajes que tienen como fin realizar actividades recreativas en contacto directo con la naturaleza y las expresiones culturales que le envuelven con una actitud y compromiso de conocer, respetar, disfrutar y participar en la conservación de los recursos naturales y culturales. Permite tanto a anfitriones como a visitantes de obtener una experiencia única. Esta definición se puede segmentar en el tipo de interés y actividades que el turista desea y busca al estar en contacto con la naturaleza. Es así que se puede dividir en tres grandes categorías: Ecoturismo, destinado al disfrute, estudio, apreciar la naturaleza y expresiones culturales pasadas y presentes; Turismo de aventura, 
actividades recreativas-deportivas, asociadas a desafíos impuestos por la naturaleza; Turismo rural, actividades de convivencia e interacción con una comunidad rural, en expresiones sociales, culturales y productivas (SEMARNAT, 2005).

Una clasificación de importancia para lograr visualizar la conjunción de posibilidades turísticas en función a un turismo alternativo, es la realizada por Pierre Defert. Este autor, propuso en su "Essai de formulation d'une Typologie Intégrée des Resources et Activités Touristiques (TIRAT)" (1972), una de las tipologías de recursos más utilizadas en Europa, distinguiendo cuatro grandes categorías basadas en la cosmología aristotélica: Hidromo, elementos (naturales y modificados) relacionados con el agua (aguas marítimas, terrestres, playas y costas, puertos deportivos, nieve, balnearios y termas, etc.); Phitomo, elementos terrestres (modificados o no) con cierto atractivo (relieve, clima, flora, fauna, paisaje, accidentes naturales, etc.); Litomo, elementos construidos por el ser humano, con interés por su naturaleza o uso (restos arqueológicos, museos, construcciones civiles, etc.); Anthropomo o Mnémome, hace referencia a las estructuras socio-económicas (idiosincrasia, características raciales, artesanía, folclore, gastronomía) y alude también a determinados recursos y la memoria (como historia colectiva) ya sea material o basada en acontecimientos históricos, etc., (González de Souza, Jiménez, \& Martín, 2015).

El Turismo Alternativo, es un sector emergente. Surge por la necesidad de atender la demanda de los nuevos consumidores turísticos, que buscan nuevas emociones (aventura, lugares históricos, contacto con la naturaleza, etc.) e implica el cambio en el comportamiento del consumidor (Millán Vázquez de la Torre, López Guzmán, \& Agudo Gutiérrez, 2006). Según estos autores, el turismo ofrece efectos positivos sobre aspectos socio-económicos, protección y conservación del patrimonio, provee mayor contacto social para las personas locales y aumenta oportunidades de aprender sobre otras culturas, etc. Entre los efectos negativos, cambio o daño del paisaje y de valores patrimoniales de la zona, reordenación de la estratificación social, presión adicional sobre la comunidad local, cambios en los ritmos de vida, amenaza de la privacidad, presentación no autentica de las costumbres y tradiciones locales, adaptación a los deseos de los turistas, entre otros.

Keane y Quinn (1990), destacan que en la mayoría de los destinos turísticos rurales, es inviable el turismo como única fuente de ingresos, ya que las tasas de ocupación son bajas y con frecuencia la inversión requerida para crear o mejorar los servicios del turismo rural es alta, sobre todo por la gestión medioambiental de los recursos naturales vulnerables. Estos autores abogan por considerarlo como fuente alternativa generadora de ingresos en una región, el cual estará altamente influenciado por el comportamiento de otros sectores económicos.

El turismo tomado como estrategia para el desarrollo, permite dinamizar las economías regionales, diversificando la producción y mejorando la calidad de vida de los pobladores. Para ello se requiere promover las prácticas de trabajo basadas en el asociativismo, la colaboración y el intercambio para que cobren sentido la sinergia de sujetos, organizaciones y organismos de los Estados nacionales, provinciales y municipales. La participación otorga un mayor protagonismo a las mujeres y a los jóvenes en los emprendimientos y fomenta el arraigo rural, al ofrecer oportunidades de complementación de actividades e ingresos a la población local (INTA, 2015). La diversificación y diferenciación de actividades económicas, aprovechando encadenamientos entre ellas, incrementan el valor agregado en origen y la reinversión local de los ingresos generados. Mejora también la calidad de las producciones locales, al aumentar las oportunidades de comercialización de los productos de la región (Varisco, 2015).

Contextualizar la planificación del desarrollo en el caso de Iglesia, debe internalizar la concepción de Paisaje y con él Patrimonio para concebir al turismo, lo que permitiría generar el cruce de dimensiones que precisa el pensamiento complejo. Sin embargo esto, se encuentra supeditado a la participación y el compromiso de los actores intervinientes. El turismo como parte del sistema territorial, debe permitir un acceso, manejo y distribución de recursos de manera equitativa.

\section{Proceso metodológico en relación al Paisaje, Patrimonio y Turismo abordado en el Plan de ordenamiento y desarrollo territorial para el departamento Iglesia}

Esta propuesta no pretende ser exhaustiva ni acabada en sí misma. Apunta al debate y a generar una orientación, para definir los criterios esenciales que deben estar presentes ante cualquier planificación rural donde la vocación turística-patrimonial sea un factor predominante. 


\subsection{La interpretación del patrimonio local}

Para el Plan de Ordenamiento y desarrollo de Iglesia (Nozica, 2017) se planteó teniendo en cuenta lo expuesto, la identificación patrimonial básica en una primera instancia, exponiendo los principales referentes patrimoniales del departamento de Iglesia por parte del equipo científico. Luego, en una segunda instancia de talleres, se procedió a discutir aquel primer reconocimiento patrimonial local, con la participación de actores/agentes del territorio por medio de encuestas y debates. Se puede definir así, los diferentes bienes patrimoniales reconocidos, volcados en una Clasificación Patrimonial propuesta según los tipos de interés (ver Tabla 1).

Por otro lado se genera una valoración social de los mismos que varía según una escala de 1 al 4 de abordaje cualitativo (considerando la variación de 1= baja a 4= alta). Además, se define así un valor de

Tabla 1: Clasificación patrimonial: Tipos de patrimonio y nomenclatura según bienes patrimoniales y tipo de interés.

\begin{tabular}{|c|c|c|c|c|}
\hline & \multicolumn{2}{|c|}{ Tipo de Patrimonio } & \multirow{2}{*}{$\begin{array}{l}\text { Bienes patrimoniales } \\
\text { Reservas, Parques Naturales } \\
\text { Áreas Naturales } \\
\text { Ecosistemas frágiles }\end{array}$} & \multirow{2}{*}{\begin{tabular}{|l|} 
Tipo de interés \\
Paisajístico Ambiental \\
\end{tabular}} \\
\hline \multirow{7}{*}{ 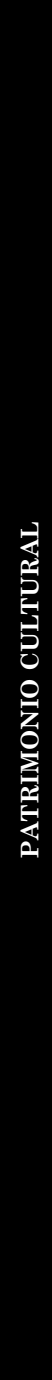 } & \multirow[t]{2}{*}{ PN. } & N. & & \\
\hline & & Nr. & $\begin{array}{l}\text { Recursos u elementos Naturales de } \\
\text { interés }\end{array}$ & Paisajístico Ambiental \\
\hline & \multirow[t]{2}{*}{$\begin{array}{l}\text { PCM. } \\
\text { Patrimonio } \\
\text { Cultural } \\
\text { Mueble }\end{array}$} & \multirow[t]{2}{*}{$\begin{array}{l}\text { Ph. } \\
\text { Bienes de valor } \\
\text { Histórico }\end{array}$} & $\begin{array}{l}\text { Etnográficos } \\
\text { Documentos } \\
\text { Manuscritos Mobiliario } \\
\text { Vestuario } \\
\text { Instrumentos Musicales }\end{array}$ & Histórico Cultural \\
\hline & & & $\begin{array}{l}\text { Artes plásticas: Cerámica, orfebrería, } \\
\text { elementos arquitectónicos artísticos, } \\
\text { religiosos, funerarios, militares. } \\
\text { Objetos valorados x una cultura. }\end{array}$ & Artístico arquitectónico \\
\hline & \multirow[t]{2}{*}{$\begin{array}{l}\text { PCI. } \\
\text { Patrimonio } \\
\text { Cultural } \\
\text { Inmueble }\end{array}$} & $\begin{array}{l}\text { Pe. } \\
\text { Patrimonio } \\
\text { Edificado }\end{array}$ & $\begin{array}{l}\text { Áreas y Sitios históricos } \\
\text { Áreas Arqueológicas } \\
\text { Edificio: urbano, rural, industrial, } \\
\text { vernáculo, popular, modesto } \\
\text { Espacios públicos } \\
\text { Ciudades Históricas } \\
\text { Centros históricos } \\
\text { Tejidos históricos }\end{array}$ & $\begin{array}{l}\text { Histórico Cultural } \\
\text { y/o } \\
\text { Artístico arquitectónico }\end{array}$ \\
\hline & & $\begin{array}{l}\text { Pp. } \\
\text { Paisajes u áreas } \\
\text { de interés cultural }\end{array}$ & $\begin{array}{l}\text { Paisajes Diseñados (Embalse, Parques, } \\
\text { Jardines Históricos) } \\
\text { Paisajes desarrollados orgánicamente } \\
\text { a) Vestigio o fósil. } \\
\text { b) Paisaje Viviente (ej. Quebrada de } \\
\text { Humahuaca, Jujuy) } \\
\text { Paisajes Asociativos (ej. Santuario } \\
\text { Virgen Copacabana. Bolivia) } \\
\text { Áreas Arqueológicas } \\
\text { Áreas Paleontológicas u Etnográficas }\end{array}$ & $\begin{array}{l}\text { Histórico Cultural } \\
\text { y/o } \\
\text { Paisajístico Ambiental }\end{array}$ \\
\hline & $\begin{array}{l}\text { PI } \\
\text { Patrimonio } \\
\text { Inmaterial }\end{array}$ & $\begin{array}{l}\text { Pi. } \\
\text { Manifestaciones } \\
\text { culturales por } \\
\text { tradición }\end{array}$ & $\begin{array}{l}\text { Formas del lenguaje } \\
\text { Manifestaciones del folclore } \\
\text { Mitos, leyendas, tradiciones } \\
\text { Tradición Oral, costumbres } \\
\text { Manifestaciones artísticas simbólicas } \\
\text { de una tradición } \\
\text { Danzas tradicionales, propias de una } \\
\text { cultura determinada } \\
\text { Rituales religiosos } \\
\text { Arte culinaria tradicional } \\
\text { Conocimientos sobre la sociedad y la } \\
\text { naturaleza. }\end{array}$ & Interés Inmaterial \\
\hline
\end{tabular}

Fuente: Elaboración propia. 
uso y de consumo (con la misma escala de valoración), en relación a lo que destaca Marina Waisman (1993) como los dos tipos de valores patrimoniales que deben reconocerse en la valoración social. El valor de consumo de un bien patrimonial, se evalúa tanto en la valoración científica como la social, e implica las posibilidades de aprovechamiento con fines económicos. El valor de uso, es el que prioriza el valor que representa la identidad cultural de la comunidad. Esto permite definir las estrategias a seguir con cada bien, y las formas de abordaje, ya que un valor de uso alto, restringirá las posibilidades de consumo a nivel turístico y viceversa.

La valoración Social implica el reconocimiento de cada bien expuesto y la relación identitaria de los grupos sociales involucrados con el bien material o inmaterial (rasgos propios y consciencia que el individuo o colectividad posea del bien). Se debe intentar captar actores vinculados, identidad/es y la pertenencia al bien, hechos, actividades, usos o aprovechamiento, como también la capacidad evocativa del bien (la memoria colectiva) interpretando el mensaje o valor testimonial.

Este reconocimiento patrimonial, permite plasmar espacialmente el potencial distribuido en el territorio. Prescindir de una matriz de reconocimiento y delimitación espacial del patrimonio, independientemente de la forma de hacerlo, determina la falta de compromiso con la sociedad y su entorno natural.

Una tercera instancia consistió en la valoración científica de acuerdo al resultado generado en la primer y segunda instancia. La misma, con una escala de valoración del 1 al 4 cuali-cuantitativa (considerando 1, baja y 4, alta). En esta instancia se analizan las variables dispuestas en la Tabla 2, según los tipos de interés patrimonial, correlativos a la Tabla 1.

Tabla 2: Variables de Valoración cientifica generales según el interés patrimonial.

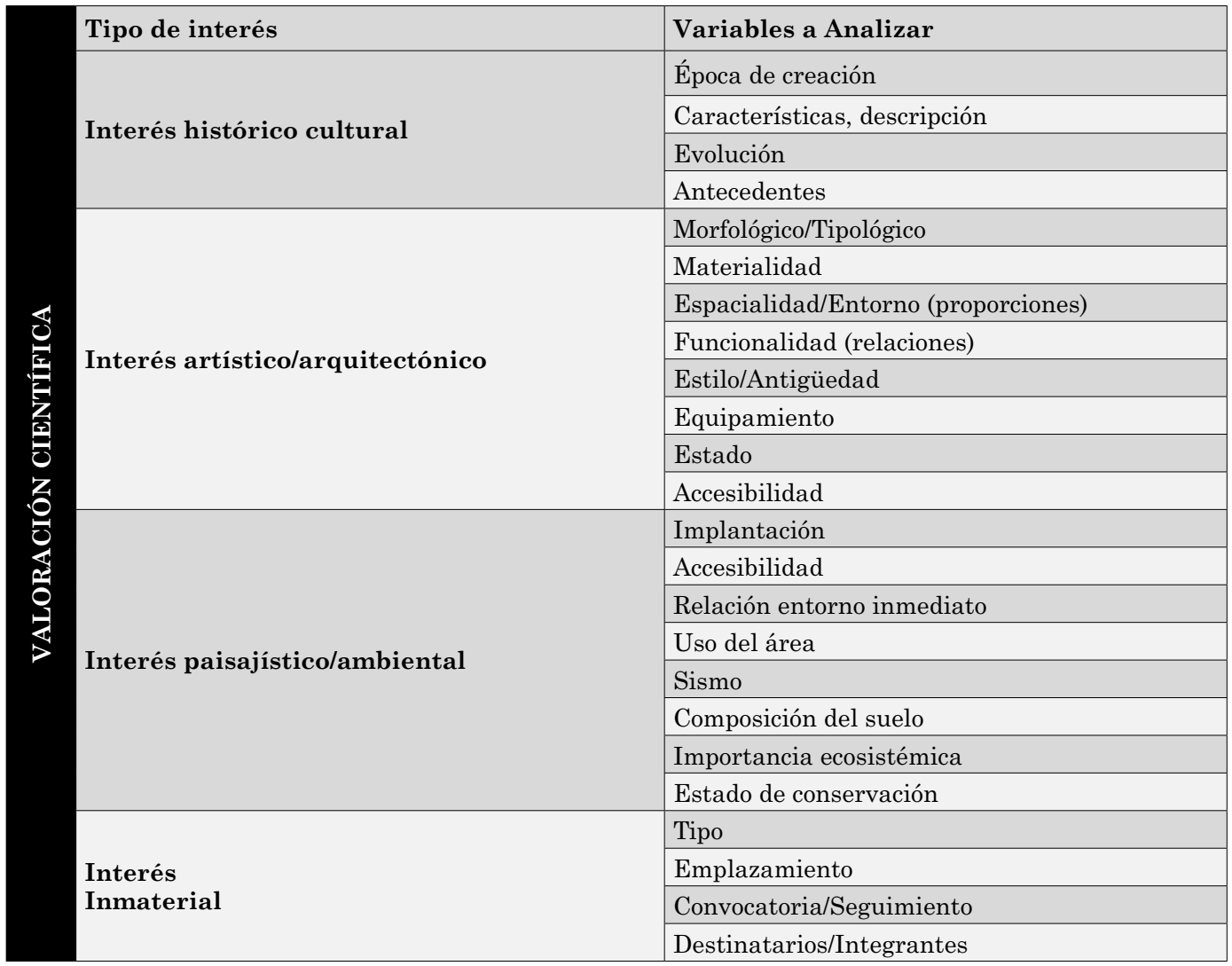

Fuente: Elaboración propia. 
La valoración científica, evalúa las condiciones físicas como también el contexto natural y social del patrimonio que no siempre es correlativo a la valoración social. En cada recurso patrimonial, se pueden observar elementos de importancia que no se ven incluidos en la evaluación social.

La valoración social en el caso e Iglesia, dio como resultado un mapa cognitivo referencial del patrimonio local, donde la comunidad asienta sus raíces. La valoración científica se plasmó en un mapa de priorización patrimonial. Ambos son complementarios para determinar las técnicas adecuadas para la protección, conservación, preservación, recuperación, rehabilitación, reciclaje, prohibición, refuncionalización, etc., como la posterior toma de decisiones. Se identifica con simbología propia para cada bien o recurso patrimonial identificado con las diferentes valoraciones detectadas.

Una vez valorados social y científicamente los bienes patrimoniales, se procedió a generar un inventario patrimonial identificando en cada uno el valor de uso y de consumo analizado.

La cuarta instancia, pretendió generar conexiones y compromisos, que los pobladores puedan manifestar, considerando la predisposición y compromiso hacia y por su patrimonio. Allí revelaron sus deseos, defensa y las posibilidades reales de gestión en el tiempo, de cada elemento del paisaje reconocido y valorado.

\subsection{Integración turística-patrimonial}

Se concibe al Turismo Alternativo, como la forma de turismo más adecuada para intervenir el territorio de Iglesia. Es por ello que se adopta la clasificación aportada por Pierre Defert, anteriormente descripta. Esta clasificación turística, permite una mejor vinculación con la realizada en función a los intereses patrimoniales (ver Tabla 1). Un aspecto importante, es la posibilidad de poner en valor a un sector importante del turismo en el territorio de Iglesia, relacionado con actividades acuáticas (Hidromo). En este caso, el departamento posee como recurso primordial, el Dique Cuesta del Viento con actividades deportivas de relevancia internacional. Por otro lado, Iglesia posee una variedad de vertientes termales de manantial (la mayoría sin estrategia de intervención) con diversa entalpía (baja, media, y alta), que pueden ser aprovechables a través de una gran diversidad de usos, tanto productivos, energéticos como turísticos (relacionados con la salud, la aventura, el deporte, la relajación, etc.) (Mattioli \& Kuchen, 2016).

La integración turística-patrimonial se basa en la valoración social y científica del patrimonio realizada anteriormente, priorizando aquellos bienes que poseen valor de consumo. Dichos bienes serán plausibles de ser parte de estrategias turísticas enfocadas al desarrollo y diversificación de usos del suelo. La consecuencia directa de esta selección, apunta a definir "áreas de actuación turística-patrimonial”, en función a dichos bienes patrimoniales geo-localizados para incorporar las estrategias turísticas, según las posibilidades o propuestas que se prefieran colectivamente. El consenso entre actores y agentes del territorio, dará como resultado la expresión de estrategias y proyectos turísticos con la consideración de las actividades asociadas (áreas complementarias). Las mismas son necesarias para el sostenimiento de la estrategia turística. Ello implica tener en cuenta a futuro, la regulación de la actividad turística que se proponga. Cada área de actuación, deberá conocer las posibilidades, limitaciones y restricciones para la transformación del uso del suelo. Esto debe corresponderse con el análisis de aptitud e impacto sobre los usos del suelo del territorio, según metodología propuesta en el plan (ver Nozica, Taber, Arroqui, y Fernandez (2009).

Las estrategias turísticas, deben poder aunar criterios, dentro de una gran variabilidad de bienes y recursos patrimoniales, para lograr una oferta atractiva y diversificada en un período de tiempo adecuado en función a la experiencia del visitante y la comunidad.

Se plantea que el enfoque debe conducir al fortalecimiento de capacidades locales y especialmente a la dinamización, asociativismo y cooperación local de los pobladores. Simplificar visualmente la vocación turística distribuida en los asentamientos del territorio, facilita la participación y organización comunitaria para habilitar articulaciones de propuestas de rutas o itinerarios turísticos. Formalizar un sistema integrado de actividades relacionadas a las cadenas de valor, permite direccionar esfuerzos y priorizar los plazos de ejecución de proyectos.

Como expresa Boisier (2004), el desarrollo depende "de un clima psicosocial positivo, de la capacidad de una específica y localizada comunidad para desatar su potencial endógeno, y del stock y articulación de los capitales intangibles".

Se muestra a en la Figura 2, la localización de las áreas de actuación de fácil visualización, según la clasificación de Defert, que habilita la vinculación patrimonial en función a diversos tipos de interés turístico. 
Figura 2: Áreas de actuación turística-patrimonial según clasificación de Pierre Defert.

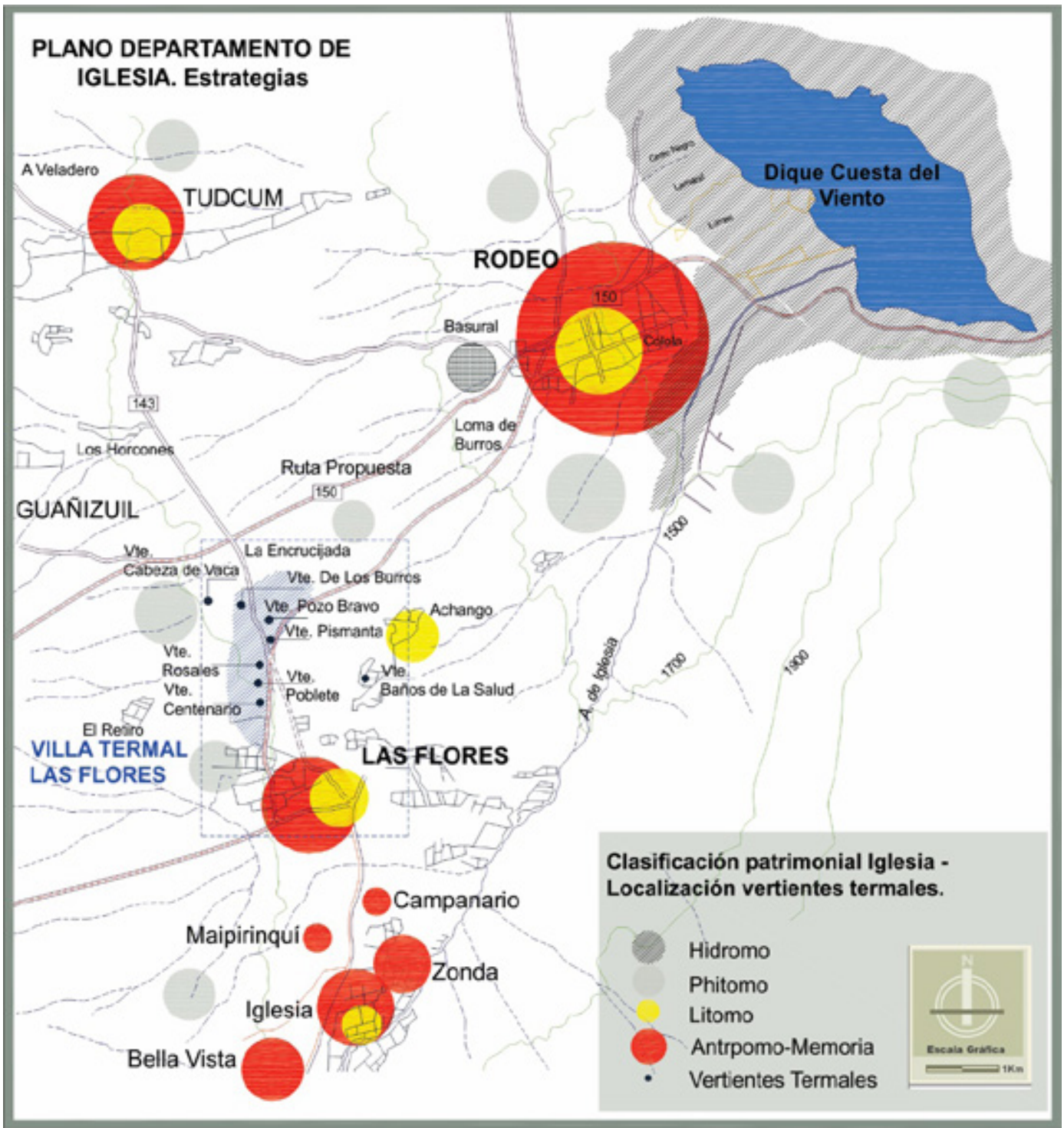

Fuente: Elaboración propia.

\section{Discusión de resultados}

El proceso generado desde el planteamiento de la pregunta rectora de este trabajo, permite exponer 5 hipótesis de trabajo. Éstas intentan encauzar un pensamiento sobre concepciones que se suponen, dirigen a formas más integrales de OT en territorios rurales, tomando el caso del Departamento rural de Iglesia y el Plan de ordenamiento y desarrollo territorial para dicho departamento. Se insiste en brindar una orientación, para definir los criterios esenciales de planificación rural donde la vocación turística-patrimonial sea un factor predominante. 
Para la contratación de las hipótesis, se desarrolla por un lado un proceso de revisión de la literatura de manera crítica y por otro, la exposición metodológica -en relación al Paisaje, Patrimonio y Turismoabordada en el PODT, a fin de evidenciar la importancia y correlación existente para el desarrollo.

Por ello se puede mostrar el siguiente gráfico que surge de la exposición realizada y concatena las hipótesis en pos de responder la pregunta rectora.

Figura 3: Explicación y concatenación conceptual para la validación de hipótesis.

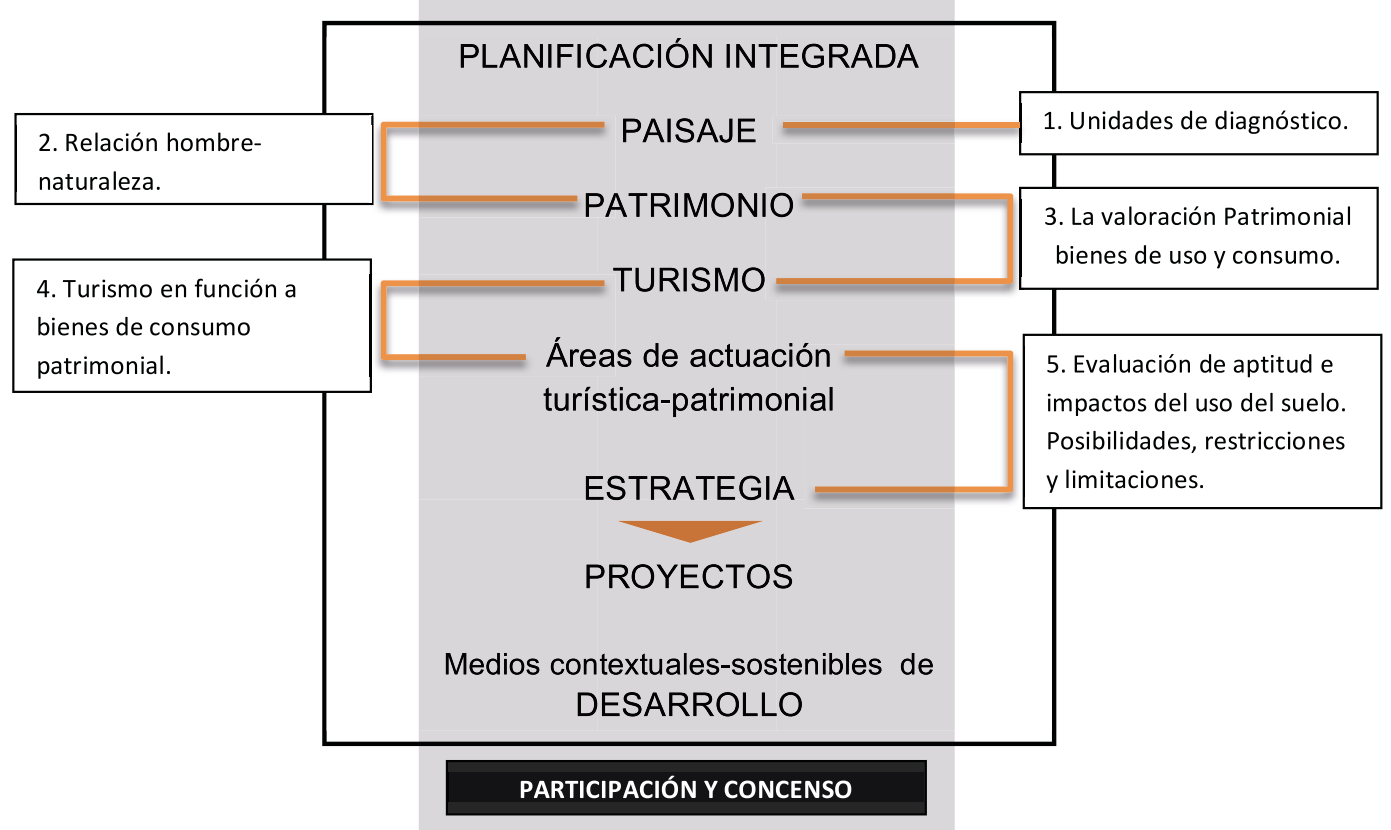

Fuente: Elaboración propia.

1) Unidades de diagnóstico: Paisaje concebido como organismo vivo, posee composición, estructura y función. Mediante enfoque de Cuenca, Eco-región y Oasis-Secano se permite entender al territorio rural de Iglesia desde los procesos que ocurren en él y definir las unidades de diagnóstico en función al Paisaje Natural y Cultural (Mattioli, 2016).

2) La relación de la naturaleza y el hombre, define al Patrimonio Cultural y Natural, con una visión antropocéntrica. Aquí se distinguen los bienes patrimoniales reconocidos y propensos a ser valorados por la comunidad local y equipo científico.

3) La valoración patrimonial científica y social brinda la base de reconocimiento local que refuerza la IDENTIDAD cultural y provee la posibilidad de establecer bienes de uso y de consumo patrimonial. Permite plasmar espacialmente el potencial distribuido en el territorio.

4) El Turismo pensado en función a bienes de consumo patrimonial, por medio de la clasificación de Pierre Defert, permite una abstracción y distribución de los intereses turísticos y oferta patrimonial geo-localizada en el territorio lo que define Áreas de actuación turística-patrimonial.

5) Las estrategias turísticas con la consideración de las actividades asociadas (áreas complementarias) que se propongan, deben corresponderse con el análisis de aptitud e impacto de usos de suelo. Este análisis permitiría precisar una regulación de la actividad turística manifestando las posibilidades, restricciones y limitaciones que deban cumplirse a fin de lograr la sostenibilidad tanto social como ambiental.

6) La traducción de la estrategia a proyectos turísticos que materialicen los consensos de actores/ agentes, ofrecería medios contextuales (el diseño de situaciones apropiadas a la escala local) y de sostenibilidad del desarrollo. 
Habiendo realizado esta exposición gráfica y explicación de los conceptos involucrados, en las hipótesis se puede afirmar que: las hipótesis 1, 2, 3 y 4 tienen validez y responden a una estructura de pensamiento, el cual ha sido abordado en el desarrollo del presente artículo. Sin embargo la hipótesis 5, no puede ser validada como tal, ya que el Turismo por sí sólo no puede determinar el desarrollo sostenible, si no es concebido como un proceso de transformación que implique la entera participación y consenso de la comunidad. Es por ello que el patrimonio y su reconocimiento, como el entendimiento del funcionamiento del sistema a través del Paisaje, se vuelven conceptos de preeminencia en estudios de planificación rural.

\section{Conclusión}

El desarrollo de este trabajo pretende, desde un posicionamiento crítico, ser un insumo para la planificación y ordenamiento territorial (OT) rural. La metodología expuesta en referencia a los principales conceptos abordados sobre el Patrimonio, el Paisaje y el Turismo, reflejan una sección del "Plan de ordenamiento y desarrollo de Iglesia", la cual se formalizó en una etapa avanzada concreción del mismo, dejando sin resolver la instancia de proposición turística. Aun así, se manifiesta la importancia estructural que dichos conceptos revisten para el desarrollo del territorio de Iglesia. Por otro lado, se logra entrever, que las formas más integrales de planificación, necesitan de procesos participativos proactivos, quedando sujeto a ello, la efectividad del proceso y la aplicación en el largo plazo.

La gestión futura del plan de ordenamiento, con la concreción de proyectos, debe lograr sentido de pertenencia de comunidad en el proceso. Esto responde a una postura científica respetuosa con el desarrollo local y sus aspiraciones. Representa una estrategia para garantizar la continuidad de la política de gestión de los recursos en el tiempo. En este sentido se expresa que; “(...) las asociaciones suponen cierta estabilidad porque se crean a partir de un consenso, de un acuerdo entre partes que quieren significar de una manera y no de otra" (Guerci \& Mugueta, 2008, pág. 3). La identidad del territorio es la alternativa del mismo en contraposición a los planes inadecuados y estructuras tradicionales que resultan ser insuficientes para la comprensión de éste como construcción histórica. El arraigo genera sentido de pertenencia y autoestima creciente, los pobladores son los verdaderos recursos (Sabaté, 2010). Si bien, la velocidad del cambio, implica rápidas respuestas, el patrimonio local, amerita un posicionamiento, negociación y participación de todos los actores/agentes locales para lograr una identidad compartida en su gestión.

Evitar situaciones superficiales, descontextualizadas, propagandísticas o especulativa de los bienes patrimoniales, implica consciencia y respeto, como aspectos éticos ineludibles y resistencia a su enajenación. En palabras de Marina Waisman, se debe hallar un equilibrio entre protección, preservación de la identidad y cambios (Waisman, 1993).

El turismo plasmado como un proceso de transformación en base a lo enunciado, puede funcionar como un factor dinamizador del desarrollo, complementario a las diferentes actividades económicas, como también facilitador de la protección, conservación y preservación patrimonial local. Permitiría generar transformaciones desde la multi-dimensionalidad que adquiere el mismo, a través del sustento cultural y natural local. Sin embargo, visualizar la vocación turística y habilitar articulaciones de actividades, propuestas e itinerarios para generar cadenas de valor, debe estar supeditado a los aspectos éticos arriba nombrados y al logro de consensos entre actores, sobre las posibilidades, limitaciones o restricciones al uso o consumo de los bienes patrimoniales en su conjunto. Así, el concepto de Paisaje y en consecuencia el de Patrimonio, se conciben como conceptos primordiales a tener en cuenta en la ordenación del territorio

Nuestra época global se impone ante lo local, generando la pérdida de las expresiones de singularidad regional con la imposición de lógicas diversas. Estas concepciones empiezan a interpelar a la planificación desde la noción sistémica, que implica formas metodológicas más integrales. Por ello, contextualizar el desarrollo sin reproducir opciones ajenas al territorio, permitiría encontrar alternativas propias que aseguren el largo plazo de las políticas plasmadas en el mismo.

\section{Agradecimientos}

Este trabajo es parte del asesoramiento y discusión del "Plan de ordenamiento y desarrollo territorial para el departamento Iglesia: los desafíos frente a la integración", por lo que se agradece a Graciela Nozica, el apoyo y colaboración permanente. El mismo fue realizado a su vez, por medio del apoyo institucional de la Facultad de Arquitectura Urbanismo y Diseño de la Universidad Nacional de San Juan (FAUD-UNSJ) y el Consejo Nacional de Ciencia y Tecnología (CONICET). 


\section{Bibliografia}

Abraham, E. 2015. CONICET Mendoza. Obtenido de CRICYT: http://www.cricyt.edu.ar/enciclopedia/ terminos/Oasis.htm

Álvarez Munárriz, L. 2010. El Patrimonio medioambiental: Los Paisajes Cuulturales. VIII ${ }^{a}$ Reunión científica. Antropología: horizontes patrimoniales educativos. Valencia: Instituto de creatividad e innovación.

Berón, N., Padilla, C., \& Rapali, N. enero - junio de 2013. Nuevo marco normativo de Ordenamiento Territorial en Mendoza: su aplicación en el Área Metropolitana. (B. Universidad Nacional de Colombia, Ed.) Bitácora(22), 97 - 108.

Boisier, S. 2004. Una (Re) Visión heterodoxa del desarrollo (Territoiral): Un imperativo categórico. 10-36.

CAAP. 2017. Carta Argentina del Paisaje. Recuperado el 5 de Abril de 2017, de Centro Argentino de Arquitectos Paisajistas: http://www.caapaisajistas.org.ar/institucional/carta_argentina_paisaje/

Centro del Patrimonio Mundial de la UNESCO . 2005. Directrices Prácticas para la aplicación de la Convención del Patrimonio Mundial. París, Francia: Comité Intergubernamental de protección del Patrimonio Mundial cultural y natural.

Consejo de Europa. 1983. Carta Europea de Ordenación del Territorio. Conferencia Europea de Ministros Responsables de la Ordenación del Territorio. Torremolinos, España.

Consejo de Europa. 2000. Convenio Europeo del Paisaje. Florencia, Italia: IPCS. Instituto del Patrimonio Cultural de España.

De Nordenflycht, J. 2002. El culto postmoderno a los monumentos: Patrimonio Local en el contexto global. Estrategias relativas al Patrimonio Cultural Mundial. La Salvaguarda en un Mundo Globalizado: Principios, Prácticas y Perspectivas (págs. 177-179). Madrid: ICOMOS.

EBITAN. 2016. Entidad Binacional Túnel de Agua Negra. Recuperado el 15 de Marzo de 2018, de http://www.ebitan.org/

García, R. 2006. Sistemas Complejos. Conceptos, métodos y fundamentación epistemológica de la investigación interdisciplinaria. Barcelona, España: Gedisa.

González de Souza, M. Á., Jiménez, A., \& Martín, D. 2015. El inventariado de los recursos turísticos. Un enfoque desde la demanda. Madrid, España: Fundación EOI.

Guerci, N., \& Mugueta, M. 30 de 10 de 2008. Entre lo proclamado y lo puesto en práctica. Contradicciones e incoherencias acerca del patrimonio cultural. El papel de las ciencias sociales. Gazeta de Antropología, 9.

Hildenbrand, A. 1996. Política de ordenación del territorio en Europa. Sevilla, España: Universidad de Sevilla, Consejería de Obras Públicas y Transportes de la Junta de Andalucía. Colección Kora.

INTA. 2015. Reunión anual de técnicos de turismo rural RAT-TUR: seis años de encuentros e intercambios. El turismo Rural como contribución al desarrollo territorial. Buenos Aires: Ediciones INTA.

Keane, M., \& Quinn, J. 1990. Rural Development and Rural Tourism. Republic of Ireland: University College Galway.

Ley $\mathrm{N}^{\circ}$ 6.549. 1994. Ley de preservación y mejoramiento del medio ambiente. (G. d. Juan, Ed.) San Juan, Argentina.

Ley $\mathrm{N}^{\circ}$ 6801. 26 de Junio de 1997. Capital, San Juan, Argentina.

Lira, L. (2006). Revalorización de la panificación del desarrollo. Santiago de Chile: CEPAL.

López, F., \& Vidargas, F. 2014. Los nuevos paradigmas de la conservación del patrimonio cultural. 50 años de la Carta de Venecia. Distrito Federal, México: Instituto Nacional de Antropología e Historia.

Massiris, A. 2002. Ordenación del Territorio en América Latina. Scripta Nova. Revista electrónica de Geografía y Ciencias Sociales, IV(125).

Massiris, A. 2005. Fundamentos conceptuales y metodológicos del ordenamiento territorial. Tunja, Colombia: Universidad Pedagógica y Tecnológica de Colombia.

Mattioli, L. 22 de Marzo de 2016. Tesis Doctoral. Construcción metodológica para el Ordenamiento Territorial del Buen Vivir de territorios rurales de Oasis Andinos. San Juan, Argentina: Facultad de Arquitectura Urbanismo y Diseño de la Universidad Nacional de San Juan.

Mattioli, L. Febrero de 2019. El buen vivir y el ordenamiento territorial. Una transición socio-ecológica en construcción. "ACE: Architecture, City and Environment", 37-62.

Mattioli, L., \& Kuchen, E. Julio de 2016. Geothermal resources as an important rural heritage to mitigate the environmental impact from territorial development in andean region. Ponte. International Scientific Researchs Journal(72), 188-197.

Mattioli, L., \& Nozica, G. (2017. Ordenamiento Territorial del Buen Vivir. Paisaje, Patrimonio y Biodiversidad, ¿Conceptos Divergentes o Convergentes? Anuário do Instituto de Geociências - UFRJ, 40(1), 26-33. 
Millán Vázquez de la Torre, M. G., López Guzmán, T., \& Agudo Gutiérrez, E. Agosto de 2006. El turismo rural como agente económico: desarrollo y distribución de la renta en la zona de Priego de Córdoba. CIRIEC-España, Revista de Economía Pública, Social y Cooperativa(55), 167-192.

Ministerio de Educacón y Deportes. Presidencia de la Nación Argentina. 2017. Dirección Nacional de Cooperación Internacional. Recuperado el 2 de Abril de 2017, de Patrimonio Mundial Natural y Cultural: http://portales.educacion.gov.ar/dnci/comision-nacional-para-la-unesco/patrimonio-mundial-capm/

Ministerio de Planificación Federal, Inversión Pública y Servicios. 2011. Plan Estratégico Territorial Avance II: Planificación Estratégica Territorial (Primera ed.). Buenos Aires, Argentina: Ministerio de Planificación Federal, Inversión Pública y Servicios.

Ministerio del Interior, Obras Públicas y Vivienda. 2017. Plan Estratégico Territorial. Recuperado el 1 de Marzo de 2018, de https://www.mininterior.gov.ar/planificacion/plan-estrategico.php

Nozica, G., \& Henríquez, G. 2014. Identificación de procesos de deterioro ambiental Valle del Tulúm, provincia de San Juan. En L. Rodriguez, La emergencia de los enfoques de la complejidad en América Latina. Desafíos, contribuciones y compromisos para abordar los problemas complejos del siglo XXI (Vol. I Tomo II, págs. 282-300). San Juan, Buenos Aires, Argentina: Comunidad de Pensamiento Complejo.

Nozica, G., \& Taber, E. 2011. Crecimiento urbano y mercado de suelo en la Ciudad de San Juan. Argentina. XXVI Congreso Internacional de Asociación Latinoamericana de Sociología. Brasil. Recife.: ALAS.

Nozica, G., De Paolis, F., \& Henríquez, M. 1996. Ambiente y procesos de deterioro. Identificación de áreas de intervención para la Gestión Ambiental en el Valle de Tulum. San Juan. Argentina: CICITCA/ Universidad Nacional de San Juan.

Nozica, G., Taber, E., Arroqui, A., \& Fernandez, H. 2009. Estudios de Macrozonificación Campo Cañada Colorada. Mendoza: Municipalidad de Malargüe, IDIH-UNSJ.

Nozica, Graciela (Coord.). 2017. Departamento de Iglesia. Plan de Ordenamiento y Desarrollo Terriorial. San Juan: FAUD-UNSJ.

ONU. 1992. Convenio sobre la Diversidad Biológica.

Sabaté, J. (2010). Paisajes culturales y proyecto territorial: un balance de treinta años de experiencia. ID_Ensayos(2), 21.

Sauer, C. 2006. La morfología del paisaje. POLIS. Revista de la Universidad Bolivariana., 5, 21.

SEMARNAT. 2005. Turismo Alternativo. México: Secretaría de Turismo, Dirección General de Desarrollo de Productos Turísticos.

Subsecretaría de Planificación Territorial de la Inversión Pública. 2016. Guía de Planificación Territorial. Buenos Aires, Argentina: Ministerio del Interior, Obras Públicas y Vivienda.

UNESCO (a). 2017. Construir la paz en la mente de los Hombres y mujeres. Recuperado el 2 de Abril de 2017, de Proteger el patrimonio y fomentar la creatividad: http://es.unesco.org/themes/proteger-patrimonio-y-fomentar-creatividad

UNESCO (b). 1972. Convención sobre la Protección del Patrimonio Mundial Cultural y Natural., (pág. 16). Paris. Francia.

UNESCO (c). 2011. Patrimonio Cultural Inmaterial. Recuperado el 27 de 03 de 2017, de ¿Qué es el patrimonio cultural inmaterial?: http://www.unesco.org/culture/ich/es/que-es-el-patrimonio-inmaterial-00003

Urzainki Mikeleiz, A. 1993. El medio rural en Euskal-Herria. Lurralde: Investigación y espacio(16), 57-74.

Varisco, C. 2015. Turismo rural: actores y recursos turísticos. X Bienal del Coloquio de Transformaciones Territoriales, (págs. 3391-3406). Córdoba.

Waisman, M. 1993. El interior de la historia. Histografía arquitectónica para uso de Latinoamericanos. (D. Serna, Ed.) Bogotá. Colombia: Escala.

\section{Notas}

1 Se conceptualiza a la micro-región como el territorio cuyo límite está definido por la existencia de interrelaciones naturales, económicas y sociales, que tienen la particularidad de producirse con una frecuencia diaria o casi cotidiana en todo el territorio de la micro-región, pero la mayor intensidad de estos intercambios se produce con el centro principal, de manera que es este centro, el que organiza el espacio y le otorga la dinámica territorial que caracteriza a la misma. Rodeo, responde a la Villa Central del Departamento.

2 El proyecto se encuentra en la etapa de precalificación; la apertura de solicitudes se realizó el día 31 de mayo de 2017.

Recibido:

$12 / 02 / 2019$

Reenviado:

$04 / 05 / 2020$

Aceptado:

$07 / 06 / 2020$

Sometido a evaluación por pares anónimos 